\title{
Claiming for a demologic approach to demographic change
}

\section{Giuseppe A. Micheli}

Strong resistance to a "grand theory" when exploring demographic processes is spreading again throughout the scientific community. No doubt, a certain sense of assertiveness that is perceptible from the statements on the Second Demographic Transition (SDT) can justify, as a reaction, the outright refusal of any all-encompassing, all-embracing theory. However, it is very hard to disagree with two major statements included in that approach: 1) the recognition of the overwhelming effect of the modernisation process on social practises, and 2) the acknowledgment that the nature of modernisation is changing into postmodernism, leading to different outcomes. But in my opinion each of these two statements needs to be better understood.

Although the SDT theory does not seem to present itself as a "grand theory", it has nevertheless triggered a new wave of generalised theoretical frameworks (candidates for middle-range theories) about the ways in which fertility changes. On this way we need to go on, looking for a recombination of these theoretical fragments to form a more comprehensive theory, endogenously including both local settings of the social world and different-instrumental, cognitive, normative, and affective - strata shaping individual decision-making concerning the main transition in life ("transitional behaviour" and "transitional choices" here denote any behaviour or choice concerning these main transitions in the life course).

As for the first statement, modernisation seems to be represented here as a gradually progressive process that spreads from some leading countries to a larger area. However, I cannot help recalling that on the contrary, demographic practises are spatially embedded "lore". Changes in family models have always acquired different forms in different settings. Up to the final convergence (and many centuries still have to pass before the modernisation will be over) every landscape is generally path-dependent. We can therefore imagine a multi-polar secularising process, converging to uniformity with reinforcement of local characteristics within local niches.

There is some evidence that cleavages in European demographic behaviour do not respect national boundaries, but rather run through and into the various countries. Europe seems split up into three different areas by two boundary lines along the $42^{\text {nd }}$ and $47^{\text {th }}$ parallels of northern latitude. The critical belt between the two parallels is a sort of Southern European orographic ridge. It is surprising to note, in the most populous countries of continental Southern Europe (especially France, Spain and Italy), the close overlap of the map of areas cited by Le Play (1984) as stem-family areas and the map of current fertility stagnation.

The Southern European orographic ridge could therefore be seen as the breeding ground both of stem-family culture and of the drastic changes in reproductive behav- 
iour to be observed at present. European patterns in fertility decline are thus regionally embedded "lore", overlapping Le Play's geography of family models.

Reher refers to this as a "path dependency" process. Generally (even in the era of globalisation) groups tend to be rooted in a territorial niche and in a subculture or "folk-lore": they act on "telluric" principles. Their demographic behaviour is thus embedded in the local anthropological structures and practises, as the outcome of a gradual sedimentation along time.

We need therefore to reconstruct the anthropological embedment of current fertility dynamics. We can no longer avoid investigating the inertial anthropological localisms in which today's demographic dynamics are embedded. To postulate an alternative between converging or diverging European demographic dynamics is only a misleading question.

A new doubt emerges from these comments. The whole of Europe has been for quite a while under the influence of a modernising process; even though its final outcome is far from behavioural standardisation. What is the reason for this? What justifies the development of different epigenetic processes in Europe leading to a fertility decline? The "reagent" might lie in the very anthropological structure of primary relations which is itself the end product of practises consolidated over time. But how can we explain that, faced with such tension between resources and expectations, various parts of the continent have used diverse adaptive strategies? What "law-like statement" can help explain why? We must try to understand the interlock of structural conditions, rational choice, practises and norms flowing into the current multi-polar scenario.

Elder and Caspi (1988) resort to a social mechanism that they defined as "principle of accentuation": it refers to the increase in salience of the characteristics of an individual or group that were already prominent even at the beginning of any individual or social discontinuity. With the principle of accentuation we arrive at the very core of our second major statement. What is the logic of this "accentuation" mechanism?

The orthodox interpretation of the current change in the demographic practises outlines that the discontinuity hinges upon an epochal change in beliefs and value orientations: as "postmodernization would refer to a process of value change", "the process of modernization so characteristic of the modern era, has led to its inevitable demise". Postmodernism thus seems to be conceived as an inflection in the modernisation process, involving just a change in beliefs. However the turning off of the propulsive power of modernity cannot be explained by a mere exhaustion of the pertaining values. This reduced definition of postmodernism can produce a harmful segmentation in our ability to understand. In my opinion we are facing, on the contrary, a discontinuity stemming not only from a change in beliefs, i.e., not only in the cognitive dimension, but also (or rather) from a new emerging state of mind.

Really, the new "economic man" is the result of a life horizon collapse, and such a collapse cannot produce but insecurity. Let us read again van de Kaa: "We have now entered a period without objectives truths, in which people will continuously seek 
their identity in a self-reflexive way. [...] Postmodernity [...] has made [people] reject formerly self-evident truths about religion, the social order, the rights and obligations of individuals, sexual behavior gender roles and so on [...]. At the cost of ever more insecurity, $[\ldots]$ their postmodernistic outlook [...] questions the fundamentals of the meaning-giving system of modern societies" (Van de Kaa, 2001).

Van de Kaa describes a decision-making process that unfolds without a specific object. The change from modernity to postmodernism is not the outcome of a mere evolution of value orientations. Rejection is not a merely cognitive process, a step in the rational decision-making process; it rather unfolds at the normative-affective level. Two key concepts deserve our attention here. The first one is the absence/loss of a centre or of "former truths". The second key word is "insecurity": a mental process without a specific object, a state of mind produced not so much by a rising "ontologic security risk" (Giddens, 1990) as by the perceived multiplication and pulverisation of Lebenswelten.

Beck (1999) argues that we live in an increasingly risk-conscious society: a consciousness perfectly coherent with the rational choice paradigm. However we cannot do without facing the extraordinary ambiguity of the concept of risk perception: if we ask ourselves why our perception of (and aversion to) risks is on the rise, we can find at least two possible answers. Risk perception can rise partly because the objective uncertainty is growing (exogenous explanation), and partly because of a rising anxiety without specific object (endogenous explanation).

Now the post-materialist values theory, associated with the SDT approach, explains the growth in risk perception as an ideational change, i. e., a change in beliefs and values. Nevertheless, unlike attitudes and beliefs, moods are non-intentional mental processes, which means they are not "about" something.

Inglehart (1997), emphasising that "postmodernization" represents a later stage of development that is linked with very different beliefs from those that characterize Modernization", posits the postmodern discontinuity into the mainstream of an essentially cognitive change. Contrary to Inglehart's opinion, there is reasonable evidence that the postmodern switch is not just a discontinuity in beliefs (or an ideational change). It is rather a new stage of modernity where the concealed face of the "accentuation of individual autonomy and self-actualisation" is emerging.

We can now pose the second question from the start in a new way: is the change from modernisation to postmodernism the outcome of a mere evolution of value orientations, or rather, as confirmed by influential representatives of twentieth-century social science, a switch in the underlying moods? And how to explain, then, the current trend of delaying life course transitions in Southern Europe?

The prevailing rational choice model (and its familistic variant as well) maintains that the shift of transitional choices into a region of legitimate indifference lets the declared expectations be countered by the costs of the transition, which are perceived to be high. The delay of life course transitions follows as a rational decision. Nevertheless, the inconsistency between the rational cost-benefit balancing and the preferences and norms learned by social influence would allegedly be reduced by changing 
values. However, a reduced dissonance is hardly confirmed by the empirical evidence in Mediterranean countries (although we do not have access to adequate longitudinal data). So, this first hypothesis is not as robust as we usually suppose.

I believe it is more useful to hypothesise that there are some states of mind interposing themselves in the sequence expectations-behaviours. If these moods change, the behaviour and the definition of the environment change as well. Therefore expectations are still conforming to the normative framework, but decisions and behaviour are hampered by a sort of blocking of moods. In this context, declared high costs are just an ex-post rationalisation to reduce the dissonance between expectations and actual behaviour.

The discrepancy between the set of internalised norms and consistent behaviour would therefore derive from positing the existence of a mechanism of interposition in the expectation-behaviour sequence, as well as an interceptor in a cerebral synapse: a sort of mechanism which cannot be identified in the cognitive constructs generally taken into account. It is as if "antagonist" mediators interposed themselves between the decisions and the stratification of awareness upon which the system of preferences and expectations is based, as happens in the processes of endocrine communication.

Indeed, the crucial demographic choices of a life course are often "decisions not to choose": there is no direct link between result and intention, and the completion of the transition from preferences to action requires a release of control exercised by reason. The rarefaction of procreative behaviour may then be read as the result of a mechanism of interception between the preference system and the decisions: something like throwing out the clutch, which makes it impossible to make a vehicle move forward, however desperately we put our foot down on the accelerator (Micheli, 2004).

This hypothesis does not at all exclude the existence of a broad range of structural factors-economic, sociological and anthropological—which are determining ones for inducing the most recent generations to make self-delimiting reproductive choices, interpreted as "rational" choices. This hypothesis resolutely denies the self-sufficiency of the main neo-classical interpretations.

Moreover, my claim to a systematic inclusion of the dispositional states in a decision-making working model may not be circumscribed within the borders of a Mediterranean "too sensitive and anxious" (too "momist") society. On the contrary I believe that, as per Elder's accentuation principle, every local system of norms, values and social practises (i.e., every local culture) has its own breaking point when exposed to environmental pressure; and that we have to open our analysis to a larger range of age-normative transitions in a life-course. Translating this hypothesis into the Coale-Lesthaeghe bottleneck model (where a precarious choice requires readiness, willingness and ability all together) would imply to simply add a fourth element, a sort of disposition to risk.

In 1672, four years before his Essay on political arithmetic, William Petty published another essay he named Political anatomy of Ireland. The switch from anat- 
omy to arithmetic was a crucial passage, and one that had been neglected too long. Unlike any other discipline, medicine at the time had already developed a method for evaluating the different states of the human body, and for the global comprehension of every symptom by taking into account the whole bulk of all other symptoms.

The aim of Petty's 1672 essay was, correctly, to try to somehow synthesise all characteristics of the dynamics of the "political body" (which we usually fragment in the social, economic, political and demographic population dynamics). When- Petty, a few years later, substituted arithmetic to anatomy in his own tool box, he was able to catch - at the very dawn of its apparition - the heuristic turning point of the emerging quantitative analysis in the exploration of the political body. Nevertheless today, as we have well developed the potential of quantitative analysis, we may have reason to go back to 1672 once more, contributing to the wealth of analytical approach the meaningfulness of the semiotic method, and introducing a more comprehensive, global sense to population dynamics (Micheli, 2003).

\section{References}

Beck, U. (1999). World Risk Society. Malden, Mass.: Polity Press. Coale, A. J. (1973). The demographic transition reconsidered. Proceedings, IUSSP Population Conference, Liège: Ordina. Vol. I, pp. 53-73.

Elder, G. H. Jr. and Caspi A. (1990). Studying lives in a changing society: sociological and personological explorations. In A. I. Rabin, R. A. Zucker, S. Frank (Eds.), Studying persons and lives (pp. 201-247). New York: Springer.

Elster, J. (1999). Alchemies of the Mind. Rationality and the Emotions. Cambridge: Cambridge University Press.

Etzioni, A. (1988). Normative-affective factors: toward a new decision-making model. Journal of economic-Psychology, 9, 125-150.

Giddens, A. (1990). The consequences of Modernity. Cambridge: Polity Press. Inglehart, R. (1997). Modernization and postmodernization: cultural, economic and political change in 43 societies. Princeton: Princeton University Press.

Le Play, F. (1884). L'organisation de la famille selon le vrai modèle signalé par l'histoire de toutes les races et de tous les temps. Tours : Alfred Mame et fils.

Lesthaeghe, R., and Vanderhoeft C. (1997). Ready, willing and able. A conceptualization of transitions to new behavioral forms. IPD-WP, 8. Brussel: Vrije Universiteit Brussel.

Micheli, G. A. (2000). Kinship, family and social network: the anthropological embedment of fertility change in Southern Europe. Demographic Research, 13. Micheli, G. A. (2003). Genius loci. Le cloisonnement régional des démographies. In J. Chasteland, M. Loriaux, L. Roussel (Eds.), L’identité de la démographie. Louvain-la-Neuve : Academia-Bruylant/L'Harmattan. 
Micheli, G. A. (2004). On the verge of a familistic interpretation: familism, moods and other alchemies. In G. Dalla Zuanna and G. A. Micheli (Eds.), Strong family, familism and lowest-low fertility. New York: Kluwer Academic.

Polanyi, K. (1944). The Great Transformation. The Political and Economic Origins of Our Time. New York: Rinehart.

Reher, D. S. (1998). Family Ties in Western Europe: Persistent Contrasts. Population and Development Review, 24, 203-234.

Van de Kaa, D. J. (1997). Postmodern fertility preferences: from changing value orientation to new behavior. In R. A. Bulatao and J. B. Casterline (Eds.), Global fertility transition. Population and Development Review, 27, Suppl., 290-331.

Van de Kaa D. J. (2002). Is low fertility post-modern and beyond the action of governments? In M. Macura and G. Beets (Eds.), Dynamics of fertility and partnership in Europe (pp. 13-16), New York, Geneva, United Nations. 